Article

\title{
Combining Ecosystem Service and Critical Load Concepts for Resource Management and Public Policy
}

\section{Timothy J. Sullivan}

E\&S Environmental Chemistry, Inc., P.O. Box 609, Corvallis, OR 97339, USA;

E-Mail: tim.sullivan@esenvironmental.com; Tel.: +1-541-758-5777

Received: 25 September 2012; in revised form: 1 November 2012 / Accepted: 6 November 2012 /

Published: 13 November 2012

\begin{abstract}
Land management and natural resource public policy decision-making in the United States can benefit from two resource damage/recovery concepts: ecosystem service (ES) and critical load (CL). The purpose of this paper is to suggest an integrated approach to the application of ES and CL principles for public land management and natural resource policy decision-making. One well known example that is appropriate for ES and CL evaluation is examined here: the acidification of soil and drainage water by atmospheric deposition of acidifying sulfur and nitrogen compounds. A conceptual framework illustrates how the ES and CL approaches can be combined in a way that enhances the strengths of each. This framework will aid in the process of translating ES and CL principles into land management and natural resource policy decision-making by documenting the impacts of pollution on environmental goods and services that benefit humans.
\end{abstract}

Keywords: assessment; sustainability; environmental science; land use management; natural resource

\section{Introduction}

Environmental management of public lands and natural resources is increasingly based on consideration of two concepts that combine elements of environmental science and policy: ecosystem service (ES) and critical load (CL) [1]. The ES approach identifies the services provided by nature that are important to humans. The CL approach quantifies pollutant loadings expected to cause ecological harm. Both the ES and CL concepts are closely related to the concept of total maximum daily load (TMDL) which is applied in the United States to point sources of water pollution under the Clean Water Act. These three concepts 
are rooted in the perception that important benefits flow to human society from the natural environment and that humans can diminish those benefits by unwise resource management. Virtually no effort to date has combined the ES and CL approaches into an overall framework that clearly documents the impacts of pollution on environmental goods and services that benefit humans.

There has also been a lack of agreement within the scientific, economic, and public policy research communities regarding exactly what constitutes an ES and how temporal variation in ecosystem damage and recovery trajectories should be incorporated into CL formulations. The purpose of this paper is to suggest an integrated approach to the application of ES and CL principles for public land management and natural resource policy decision-making. Acidification of soil and water by atmospheric deposition of sulfur (S) and nitrogen (N) [2] is used as an illustrative example. This topic has been the subject of extensive research over the past three to four decades in the United States, Europe, and more recently China and elsewhere in Asia. The basic principles of ES and CL are common, however, to a variety of air, soil, and water pollution and human land use issues. They stem from principles outlined in the "Tragedy of the Commons" [3], whereby overuse of a common resource leads to elimination of that resource. The ES concept is also appropriate to situations where the majority of benefits and services are largely social and difficult to quantify.

The CL is defined as the level, or load, of pollution below which significant harmful effects are not expected to occur to sensitive ecosystem elements [4]. There are uncertainties regarding what is considered to be a significant harmful effect and the time period of the intended protection. The CL is generally specified on the basis of chemical indicator dose-response functions or tipping points expressed under long-term steady-state conditions [5]. In other words, The CL specifies the pollutant load which, when applied to the ecosystem in question for a period of years to centuries, will trigger a change in a chemical indicator of biological harm at the time that the ecosystem comes into steady state with respect to that particular pollutant input level.

A dynamic, as opposed to steady-state, pollutant load can also be defined, which is specific to a particular point in time. For example, one may ask the question: what is the deposition load that is sufficiently low so as to protect certain biological resources in a certain water body if pollutant inputs occur continuously at that level until the time specified (for example, the year 2100)? This dynamic load, which includes consideration of the temporal component of ecosystem damage or recovery, is called a target load (TL).

Additional research is needed to more closely tie the ES and CL concepts together in a way that facilitates the provision of benefits to humans from the use and enjoyment of nature's products. The purpose of the conceptual framework outlined here is to make these connections more explicit. Informed decisions will be rooted in consideration of multiple stressors; their causes, logistics and costs of control; and the perceived importance and/or value of impacted services.

In the following section, I present a general overview discussion of ES. It is followed by a more detailed discussion combining ES and CL, using soil and water acidification as an example.

\section{Analysis}

I adopt the premise that regulatory and land management agencies and researchers working at the interface between environmental science and public policy will benefit from application of a definition 
of ES that captures components of nature that can be measured, mapped, stacked (i.e., multiple ESs considered across the same geographical area simultaneously), and valued [6,7]. Value can be, but is not necessarily required to be, expressed in monetary terms. Value can also be expressed in terms of societal preference. Each ES should be geographically referenced and expressed in generally comparable units of measure [8,9]. This allows comparison of loss or gain in ES across space and across time. Services that can be measured and stacked to facilitate prioritization of key regions or watersheds are especially important to human well-being because those key areas might provide a multitude of services, provide services that are located in proximity to centers of human population, or provide services that are highly valued. Assignment of value is critical to examination of trade-offs between the value of ES lost due to ecosystem damage versus the cost of preservation or restoration. The barrier inhibiting translation of services into a common currency remains an important limitation of the ES approach. There are also important challenges regarding application of the ES concept to resource management and formulation of public policy.

The Millennium Ecosystem Assessment (MEA) [1] and other notable publications [7] identified and classified ESs into groups:

- provisioning (e.g., food, fiber);

- supporting (e.g., nutrient cycling);

- regulating (e.g., climate control, water flow regulation); and

- cultural (e.g., spiritual enrichment, intellectual stimulation).

However, the supporting and regulating services identified by MEA [1] are generally inconsistent with a definition of ES that is measurable, mappable, and capable of being stacked and valued along with other ESs. There is a need for more operationally defined units of account [10]. In addition, there are difficulties with respect to double-counting of intermediate products or services in situations where the value of one ES is embedded within the value of another ES. This double-counting is problematic with respect to stacking and monetizing ESs. Intermediate products, services, processes, and cycles are not final ESs, and in many cases they cannot be mapped. By virtue of their intermediate nature, their value is captured in an accounting of final ESs.

Boyd and Banzhaf [10] presented an economic perspective on ESs that highlighted the importance of separating intermediate and final services for economic valuation. It is these final ESs that satisfy the need to measure, stack, map, and value ESs. Interim products, functions, processes, and cycles are intermediate to, or contribute to, final ESs, but are not themselves final ESs. Furthermore, such attributes as spiritual enrichment, relaxation, and intellectual stimulation are more properly classified as social benefits of ESs. This latter distinction reflects the difficulties associated with objectively valuing, mapping, and stacking such social benefits. They are clearly important to human well-being, but do not constitute final ESs under a definition that is focused on discrete end product components of nature. The distinctions among sources of human well-being, intermediate products, social benefits, ecological functions or processes, and final ESs (Table 1) are critical to application of the ES concept to the problem of assessing the environmental impacts and associated costs of atmospheric deposition of acidifying compounds and many other environmental science/policy challenges. 
Table 1. Some key terms that are central to the ecosystem service concept based on the example of acidification effects on recreational fishing.

\begin{tabular}{|c|c|c|}
\hline Term & Description & Examples \\
\hline Final ecosystem service & $\begin{array}{l}\text { End product component of nature that yields } \\
\text { human well-being }\end{array}$ & Sport fishery, surface water \\
\hline Intermediate service & $\begin{array}{l}\text { Intermediate product needed to support } \\
\text { final ESs }\end{array}$ & Water quality needed to support that fishery \\
\hline Value & $\begin{array}{l}\text { Importance to people, expressed in monetary } \\
\text { or non-monetary terms }\end{array}$ & $\begin{array}{l}\text { Opportunity to fish in an aesthetically } \\
\text { pleasing location that contains suitable } \\
\text { sport fish }\end{array}$ \\
\hline Function/process & $\begin{array}{l}\text { Intermediate step that contributes to } \\
\text { the service }\end{array}$ & $\begin{array}{l}\text { Nutrient cycling, cleansing of drainage } \\
\text { water as it flows through soil, } \\
\text { microclimate regulation }\end{array}$ \\
\hline $\begin{array}{l}\text { Social benefit or source } \\
\text { of well-being }\end{array}$ & $\begin{array}{l}\text { Arises from the human use of an ES, often in } \\
\text { combination with other conventional goods } \\
\text { and services }\end{array}$ & Recreation, spiritual enrichment, relaxation \\
\hline
\end{tabular}

Given the importance of these considerations, and in keeping with the economic issues raised by Boyd and Banzhaf [10], I define a final ES as:

An endpoint component of nature that can be enjoyed, consumed, or used by people to generate human well-being and that can be measured, stacked, mapped, and valued using a common currency.

Resource management and public policy should focus in large part on these final ESs, which are determined by the processes, cycles, and intermediate services that are the subject of considerable ecological research. Social benefits derived from intermediate and final ESs should also be considered, but in most cases will not be measured, valued, stacked, and mapped.

A general conceptual model for incorporation of CL (including associated TL) and ES into a framework for assessing environmental effects of atmospheric $\mathrm{S}$ and $\mathrm{N}$ deposition and the preservation of sustainable ecosystems and their services is shown in Figure 1. I start by identifying the forest, soil, stream, and/or lake as potentially acid-sensitive resource(s) for which we desire to develop CLs and/or TLs to support resource damage assessment. Identification of services considered to be at risk or already damaged informs decisions regarding prioritizing resources to be protected or restored. The overarching goal is to protect, maintain, and restore ESs; the CL provides one management tool to assist in accomplishing this goal. The decision of which resource(s) to protect will determine available options in proceeding clockwise around the science/policy assessment loop (shown in the schematic illustration in Figure 1). After a resource has been identified for protection or for recovery from damage, the next step is to select an indicator of resource condition. The indicator facilitates tracking the biological health of the resource. Because of difficulties in monitoring biological conditions directly, a chemical indicator is often used that reflects the likelihood of biological damage. For protecting terrestrial resources (forest, soil) from acidification, the indicator might be soil base saturation (BS) or soil solution Ca:Al molar ratio. For protecting aquatic resources in this acidification example, the surface water acid neutralizing capacity (ANC) is most commonly used [11]. Note that at some locations, surface water ANC has been improving 
in response to emissions controls, yet soil acid-base status appears to be continuing to deteriorate under ambient acidic deposition loads [12]. One or more critical threshold criteria are specified for each indicator, based on known tipping points or dose-response relationships. These threshold criteria connect the indicator with a biological response, and that response is often linked to provision of one or more ESs. An important aspect of ESs is the ability to make tradeoffs and to recognize that land managers can manage for ESs that are supplied by an ecosystem that is not pristine. Ecosystem health can be partially compromised yet the impacted ecosystem continues to support specific beneficial uses. The biological response can be reflected on the basis of one or more ecosystem attributes, such as taxonomic richness, the quality of the habitat to support given biota, or the presence of an indicator species, a keystone species, or a species of special value. ANC threshold criteria are commonly set at $0 \mu \mathrm{eq} / \mathrm{L}, 20 \mu \mathrm{eq} / \mathrm{L}, 50 \mu \mathrm{eq} / \mathrm{L}$, or $100 \mu \mathrm{eq} / \mathrm{L}$ for various aquatic biota protection levels $[2,5,13]$.

Figure 1. General conceptual model for assessment of acidification effects of atmospheric $\mathrm{S}$ and $\mathrm{N}$ deposition, incorporating the critical load and ecosystem service concepts. BS is soil percent base saturation; ANC is surface water acid neutralizing capacity.

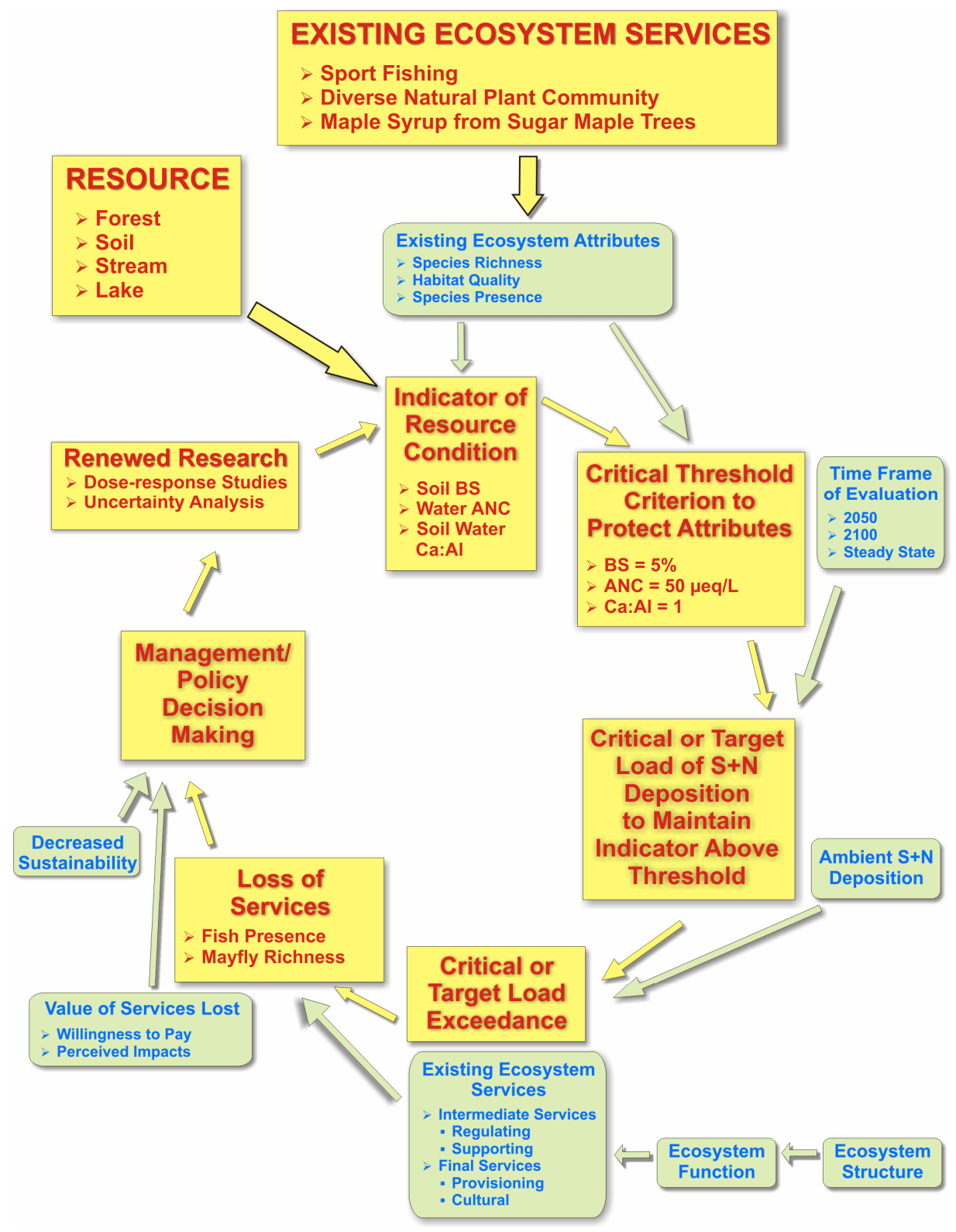


The CL is calculated using either a steady-state or dynamic model, of which there are multiple choices $[2,5]$. The CL or TL is calculated to protect against $S, N$, or $(S+N)$ deposition damage. The resulting calculated deposition input that the ecosystem can tolerate without experiencing biological harm is quantitatively associated with an indicator and critical threshold value(s) for that indicator.

The CL or TL provides an indication of the point at which the ecosystem may begin losing ESs and transitioning from a sustainable functioning ecosystem to one that is not functioning properly and is no longer considered sustainable. Thus, the CL concept provides a tool that enables the implementation of ES-based decision making.

On its own, the CL does not predict whether the ecosystem under investigation actually experiences, or will in the future experience, any biological harm. To make that determination, the ambient pollutant load must also be considered. If the ambient deposition is higher than the CL or TL that the ecosystem can tolerate, the ecosystem is said to be in exceedance [5]. Transitioning between a condition of non-exceedance to a condition of exceedance does not mean that the ecosystem is currently experiencing damage. The transition from non-exceedance to exceedance, or vice versa, indicates a change in the probability that ESs will be lost or recovered, depending on whether the starting point is an undamaged or a damaged state. For undamaged systems, exceedance signifies that if deposition is continued at the current exceedance level, damage will occur at the time point specified for the analysis (e.g., 2100, upon reaching steady-state condition). The converse also applies: transitioning from exceedance to non-exceedance suggests that recovery will occur at the future time specified in the CL analysis.

If the pollutant input level is found to be in exceedance, there is an increased likelihood that there will be a loss of one or more ESs. For example, aquatic ESs that could be lost include native brook trout presence or a portion of the taxonomic richness or biodiversity of fish. Benthic stream macroinvertebrates (e.g., mayflies) [13] or lake zooplankton (e.g., crustaceans, rotifers) [14] might also be impacted, perhaps representing loss of intermediate ESs. Terrestrial ESs at risk might include the presence of a diverse natural plant community or the syrup and lumber produced from acid-sensitive sugar maple trees. Based on the estimated loss or gain of ESs, management or policy decisions might be made to change emissions regulations, implement remediation actions, or take other management steps. If it is judged that the indicator threshold criteria are not sufficiently known, or that the assessment uncertainty is too high, additional research or analysis may be warranted.

\section{Discussion}

Considering the impacts of acidifying atmospheric emissions on various major components of the natural environment as an example (Figure 1), natural ESs are provided in association with water resource condition, water flow regulation, biodiversity, and soil and forest resource condition. Each of these benefit areas can be adversely impacted by acidifying emissions. Natural background conditions during the preindustrial period did not include human activities associated with the production of food, electricity, and transportation that would generate acidifying emissions. These drivers of acidification produced conventional services for humanity but also reduced the provision of natural ESs. Thus, development of conventional goods and services comes at a price, in that each of the natural services can be reduced in comparison with its level of provision under background conditions. The loss of natural services can be large in the absence of emissions controls. Under substantial emissions controls, however, the food, 
electricity, and transportation goods and services can be provided with only minimal loss of natural ESs. The CL approach allows identification of the level of emissions controls (and consequent deposition loading) that are needed to minimize the loss of important final ESs as a consequence of food, energy, and transportation development.

The CL concept is increasingly being used as an important part of the basis for air pollution emissions permitting decisions pursuant to the Clean Air Act Amendments of 1990 and the Prevention of Significant Deterioration (PSD) permit application process $[15,16]$. This process combines selection of air quality related values (AQRVs) to be protected in federal Class I areas (areas such as wilderness areas and national parks that receive maximum federal protection from air pollution degradation) with calculation of atmospheric deposition analysis thresholds required to prevent CL exceedance $[17,18]$.

The next step in the process of implementing the CL/ES approach is to determine the locations where the CL or TL is most commonly exceeded. This can be done for acidification effects using process-based ecosystem response models, steady-state mass balance models, and/or extrapolation of site-specific model output parameters to the regional landscape $[19,20]$. Regional CL calculation provides the basis for mapping CL exceedance and the loss or gain of ESs. Differential mapping of multiple CL values for protecting different resources and beneficial uses allows ESs to be stacked. Thus, varying ES gains and losses in different portions of the landscape can be identified, in some cases quantified, and combined.

This science/policy decision loop (Figure 1) illustrates how the CL and ES concepts can be combined in a way that enhances the strengths of each. The CL helps to bridge the gap between change in water chemistry and biological response, and establishes threshold(s) for acceptable change. The ES framework places those chemical and biological changes into terms and units that have clear meaning to people. In the pathway from chemical indicator of adverse impact to effects on ESs, there are five critical areas in need of further research: (1) dose response relationships and critical thresholds or tipping points that indicate probable biological harm; (2) ecological production functions that translate biological harm or recovery into changes in final ESs; (3) human values that determine the components of nature that directly enhance human well-being so that a mappable set of final ESs can be developed; (4) translation of ESs into a common currency (monetary or otherwise); and (5) existence of societal barriers that limit implementation of abatement actions or changes in human behavior.

One important aspect of the CL approach is its focus on steady-state conditions. The CL calculation is generally specific to a future point in time at which the ecosystem will come into steady state with respect to air pollution inputs. Thus, it represents the long-term sustainable pollutant level that is protective of ecosystem health. However, a given watershed may take many decades or centuries to reach the steady-state condition under a scenario of altered atmospheric deposition. Furthermore, ongoing changes in climate, land use, and non-native species may prevent the steady-state condition from ever being reached. Land managers may require target load estimates that are targeted to a particular management time frame, such as the year 2050 or 2100 . Thus, the importance of management timelines must be included in applying CL principles to ES calculations.

\section{Conclusions}

The CL and ES concepts are combined here into a conceptual framework that enhances the strengths of each and facilitates land and water management and natural resource policy decision-making. It allows 
the effects of human activities to be documented in terms that are rooted in scientific understanding, but that also are understandable to the general public. Application of CL to an ES assessment improves the ES analysis by linking the loss or gain of ES to the amount of pollution that the ecosystem can tolerate.

This discussion is, by necessity, anthropocentric. Some may argue that natural resources have intrinsic or morality-based existence value and that it is inappropriate to frame the value of nature solely in the context of effects on human well-being. This may be a valid criticism. Nevertheless, if the effects of human activities on natural resource elements are not documented in terms that are understandable, accessible, and recognized to be important to and by the non-scientific public, such values are unlikely to be included in the environmental calculations, trade-offs, and decision-making that will have to be made.

\section{Acknowledgments}

This research was supported by a contract from the U.S. Environmental Protection Agency to SRA International, Inc. Helpful suggestions on an earlier draft of the paper were provided by B. Cosby, R. Dennis, J. Lynch, and J. Sullivan.

\section{References}

1. Millennium Ecosystem Assessment (MEA). Living Beyond Our Means: Natural Assets and Human Well-Being; Island Press: Washington, DC, USA, 2005.

2. U.S. Environmental Protection Agency. Integrated Science Assessment for Oxides of Nitrogen and Sulfur Ecological Criteria (Final Report); EPA/600/R-08/082F; Office of Research and Development, National Center for Environmental Assessment: Research Triangle Park, NC, USA, 2008.

3. Hardin, G. The tragedy of the commons. Science 1968, 162, 1243-1248.

4. Nilsson, J.; Grennfelt, P. Critical Loads for Sulphur and Nitrogen; Miljorapport 1988:15; Nordic Council of Ministers: Copenhagen, Denmark, 1988.

5. Henriksen, A.; Posch, M. Steady-state models for calculating critical loads of acidity for surface waters. Water Air Soil Pollut. Focus 2001, 1, 375-398.

6. Hein, L.; van Koppen, K.; de Groot, R.S.; van Ierland, E.C. Spatial scales, stakeholders and the valuation of ecosystem services. Ecol. Econ. 2006, 57, 209-228.

7. Carpenter, S.R.; Mooney, H.A.; Agard, J.; Capistrano, D.; DeFries, R.S.; Diaz, S.; Dietz, T.; Duraiappah, A.K.; Oteng-Yeboah, A.; Pereira, H.M.; et al. Science for managing ecosystem services: Beyond the Millennium Ecosystem Assessment. Proc. Natl. Acad. Sci. USA 2009, 106, 1305-1312.

8. Gimona, A.; van der Horst, D. Mapping hotspots of multiple landscape functions: A case study on farmland afforestation in Scotland. Landsc. Ecol. 2007, 22, 1255-1264.

9. Naidoo, R.; Balmford, A.; Costanza, R.; Fisher, B.; Green, R.E.; Lehner, B.; Malcolm, T.R.; Rickets, T.H. Global mapping of ecosystem services and conservation priorities. Proc. Natl. Acad. Sci. USA 2008, 105, 9495-9500.

10. Boyd, J.; Banzhaf, S. What are ecosystem services? The need for standardized environmental accounting units. Ecol. Econ. 2007, 63, 616-626. 
11. Sullivan, T.J.; Cosby, B.J.; Webb, J.R.; Dennis, R.L.; Bulger, A.J.; Deviney, F.A., Jr. Streamwater acid-base chemistry and critical loads of atmospheric sulfur deposition in Shenandoah National Park, Virginia. Environ. Monit. Assess. 2008, 137, 85-99.

12. Sullivan, T.J.; Fernandez, I.J.; Herlihy, A.T.; Driscoll, C.T.; McDonnell, T.C.; Nowicki, N.A.; Snyder, K.U.; Sutherland, J.W. Acid-base characteristics of soils in the Adirondack Mountains, New York. Soil Sci. Soc. Am. J. 2006, 70, 141-152.

13. Cosby, B.J.; Webb, J.R.; Galloway, J.N.; Deviney, F.A. Acidic Deposition Impacts on Natural Resources in Shenandoah National Park; NPS/NER/NRTR-2006/066; Northeast Region, National Park Service, U.S. Department of the Interior: Philadelphia, PA, USA, 2006.

14. Nierzwicki-Bauer, S.A.; Boylen, C.W.; Eichler, L.W.; Harrison, J.P.; Sutherland, J.W.; Shaw, W.; Daniels, R.A.; Charles, D.F.; Acker, F.W.; Sullivan, T.J.; Momen, B.; Bukaveckas, P. Acidification in the Adirondacks: Defining the biota in trophic levels of 30 chemically diverse acid-impacted lakes. Environ. Sci. Technol. 2010, 44, 5721-5727.

15. Porter, E.; Johnson, S. Translating science in policy: Using ecosystem thresholds to protect resources in Rocky Mountain National Park. Environ. Pollut. 2007, 149, 268-280.

16. Burns, D.A.; Blett, T.; Haeuber, R.; Pardo, L. Critical loads as a policy tool for protecting ecosystems from the effects of air pollutants. Front. Ecol. Environ. 2008, 6, 156-159.

17. U.S. Forest Service; National Park Service; U.S. Fish and Wildlife Service. Federal Land Managers' Air Quality Related Values Work Group (FLAG): Phase I Report-Revised (2010); Natural Resource Report NPS/NRPC/NRR—2010/232; National Park Service: Denver, CO, USA, 2010.

18. U.S. Forest Service; National Park Service; U.S. Fish and Wildlife Service. Federal Land Managers' Interagency Guidance for Nitrogen and Sulfur Deposition Analyses: November 2011; NPS/NRSS/ARD/NRR—2011/465; National Park Service: Denver, CO, USA, 2011.

19. McDonnell, T.C.; Cosby, B.J.; Sullivan, T.J. Regionalization of soil base cation weathering for evaluating stream water acidification in the Appalachian Mountains, USA. Environ. Pollut. 2012, $162,338-344$.

20. Reynolds, K.M.; Hessburg, P.F.; Sullivan, T.; Povak, N.; McDonnell, T.; Cosby, B.; Jackson, W. Spatial Decision Support for Assessing Impacts of Atmospheric Sulfur Deposition on Aquatic Ecosystems in the Southern Appalachian Region. In Proceedings of the 45th Hawaiian International Conference on System Sciences, Maui, HI, USA, 4-7 January 2012; pp. 1197-1206.

(C) 2012 by the authors; licensee MDPI, Basel, Switzerland. This article is an open access article distributed under the terms and conditions of the Creative Commons Attribution license (http://creativecommons.org/licenses/by/3.0/). 